\title{
Dysregulation of the placental renin-angiotensin system in human fetal growth restriction
}

\author{
Sarah J Delforce ${ }^{1,2,3}$, Eugenie R Lumbers ${ }^{1,2,3}$, Stacey J Ellery ${ }^{7}$, Padma Murthi ${ }^{4,5,6,7}$ and \\ Kirsty G Pringle $\mathrm{e}^{1,2,3}$ \\ ${ }^{1}$ School of Biomedical Sciences and Pharmacy, University of Newcastle, Newcastle, New South Wales, Australia, \\ ${ }^{2}$ Priority Research Centre for Reproductive Sciences, University of Newcastle, Newcastle, New South Wales, \\ Australia, ${ }^{3}$ Hunter Medical Research Institute, Newcastle, New South Wales, Australia, ${ }^{4}$ Department of \\ Pharmacology, Biomedicine Discovery Institute, Monash University, Clayton, Victoria, Australia, ${ }^{5}$ Department of \\ Maternal-Fetal Medicine, Pregnancy Research Centre, Royal Women's Hospital, Parkville, Victoria, Australia, \\ ${ }^{6}$ Department of Obstetrics \& Gynaecology, University of Melbourne, Parkville, Victoria, Australia and ${ }^{7}$ The Ritchie \\ Centre, Hudson Institute of Medical Research, Melbourne, Victoria, Australia
}

Correspondence should be addressed to K G Pringle; Email: kirsty.pringle@newcastle.edu.au

\begin{abstract}
Fetal growth restriction (FGR) is a pregnancy complication wherein the foetus fails to reach its growth potential. The reninangiotensin system (RAS) is a critical regulator of placental function, controlling trophoblast proliferation, angiogenesis and blood flow. The RAS significantly influences uteroplacental blood flow through the balance of its vasoconstrictive and vasodilatory pathways. Although the RAS is known to be dysregulated in placentae from women with preeclampsia, the expression of the RAS has not yet been studied in pregnancies compromised by FGR alone. This study investigated the mRNA expression and protein levels of RAS components in placentae from pregnancies compromised by FGR. Angiotensin II type 1 receptor (AGTR1) and angiotensinconverting enzyme 2 (ACE2) mRNA levels were reduced in FGR placentae compared with control $(P=0.012$ and 0.018 respectively). Neprilysin (NEP) mRNA expression was lower in FGR placentae compared with control $(P=0.004)$. mRNA levels of angiotensinogen (AGT) tended to be higher in FGR placentae compared with control $(P=0.090)$. Expression of prorenin, AGT, angiotensin-converting enzyme (ACE) or ACE2 proteins were similar in control and FGR placentae. The renin-AGT reaction is a first order reaction so levels of expression of placental AGT determine levels of Ang II. Decreasing levels of ACE2 and/or NEP by limiting the production of Ang-(1-7), which is a vasodilator, and increasing placental Ang II levels (vasoconstrictor) may result in an imbalance between the vasoconstrictor and vasodilator arms of the placental RAS. Ultimately this dysregulation of the placental RAS could lead to reduced placental perfusion that is evident in FGR.

Reproduction (2019) 158 237-245
\end{abstract}

\section{Introduction}

Fetal growth restriction (FGR) affects $3-9 \%$ of all births (Miller et al. 2016). FGR occurs when the foetus fails to achieve its full growth potential in utero, and it is often associated with poor perinatal outcomes. There is extensive evidence indicating that an adverse prenatal environment and impaired fetal growth results in fetal programming, which predisposes the fetus to hypertension, diabetes and cardiovascular disease in adult life (Barker 2004, Warner \& Ozanne 2010). Frequently, FGR occurs because of other maternal complications in pregnancy such as preeclampsia or gestational diabetes. FGR can also have fetal (e.g. genetic defects) or placental causes (e.g. infarcts). Approximately $60-70 \%$ of FGR cases are, however, of unknown aetiology and are termed 'idiopathic FGR'
(Ghidini 1996, Resnik 2002). Evidence of additional pathological signs, including asymmetric growth and reduced amniotic fluid index, allows discrimination between FGR and small-for-gestation-age (SGA) infants who are otherwise healthy.

While the aetiology of idiopathic FGR is poorly understood, inadequate placental development, possibly related to insufficient invasion of the maternal decidua by the extravillous cytotrophoblast and impaired maternal spiral arteriole remodelling (collectively termed 'placental insufficiency') is known to contribute to pregnancy complications including FGR (Lyall et al. 2013). Perturbations in placental development resulting in placental insufficiency are characterised by under perfusion of the placenta, later in gestation, resulting in suboptimal nutrient delivery to the foetus and therefore suboptimal foetal growth (Lackman et al. 2001). 
The renin-angiotensin system (RAS) is a circulating endocrine system that regulates blood pressure and fluid volume (Fig. 1). All the components of the RAS are present in the placenta from as early as 6-week gestation, where they may act independent of the circulating RAS to regulate both villous and extravillous cytotrophoblast proliferation, extravillous cytotrophoblast migration, invasion and placental angiogenesis (Pringle et al. 2011). The placental RAS has also been shown to modulate uteroplacental blood flow in animal models (Ito et al. 2002, Moritz et al. 2010), regulate extravillous cytotrophoblast invasion in vitro (Williams et al. 2010) and placental nutrient transport (Shibata et al. 2006).

The RAS regulates these functions through two major arms. In tissues, prorenin is non-proteolytically activated by binding to its (pro)renin receptor or proteolytically activated by cathepsins and other proteases so that it is able to cleave Ang I from angiotensinogen (AGT, renin's substrate). Angiotensin I (Ang I) is then converted to the main biologically active peptide of the system (Ang II) by angiotensinconverting enzyme (ACE). Ang II, acting via the angiotensin II type 1 receptor $\left(\mathrm{AT}_{1} \mathrm{R}\right)$, promotes proliferation, angiogenesis and vasoconstriction. Ang II/AT ${ }_{1} \mathrm{R}$-induced angiogenesis is mediated through the production of angiogenic factors including vascular endothelial growth factor (VEGF) and placental growth factor (PGF) (Pan et al. 2010, Napoleone et al. 2012). This is also the local vasoconstrictor arm of the RAS.

Ang II also on the $\mathrm{AT}_{2} \mathrm{R}$ and antagonises the effects of $A T_{1} R$ activation. Alternatively, Ang I and Ang II can be cleaved by a homologue of ACE, ACE2, to produce Ang-(1-9) and Ang-(1-7), respectively. Ang-(1-9) can further be processed by ACE to produce Ang-(1-7). Ang-(1-7) acting via its receptor, Mas, also antagonises the effects of $A T_{1} R$ activation. Neprilysin is an endopeptidase that is able to produce both Ang-(1-7) from Ang I as well as Ang-(1-9) (Gafford et al. 1983). Additionally, neprilysin is able to inactivate Ang II by cleaving it into two tetrapeptides (Gafford et al. 1983). Aminopeptidases, including glutamyl aminopeptidase (ENPEP) and endoplasmic reticulum aminopeptidase 1 (ERAP1), allow the conversion of Ang II to Ang III or Ang IV, and can cause vascularisation, inflammation, vasodilation and hypertrophy. Thus, disruption of the placental RAS and the balance between these vasoactive

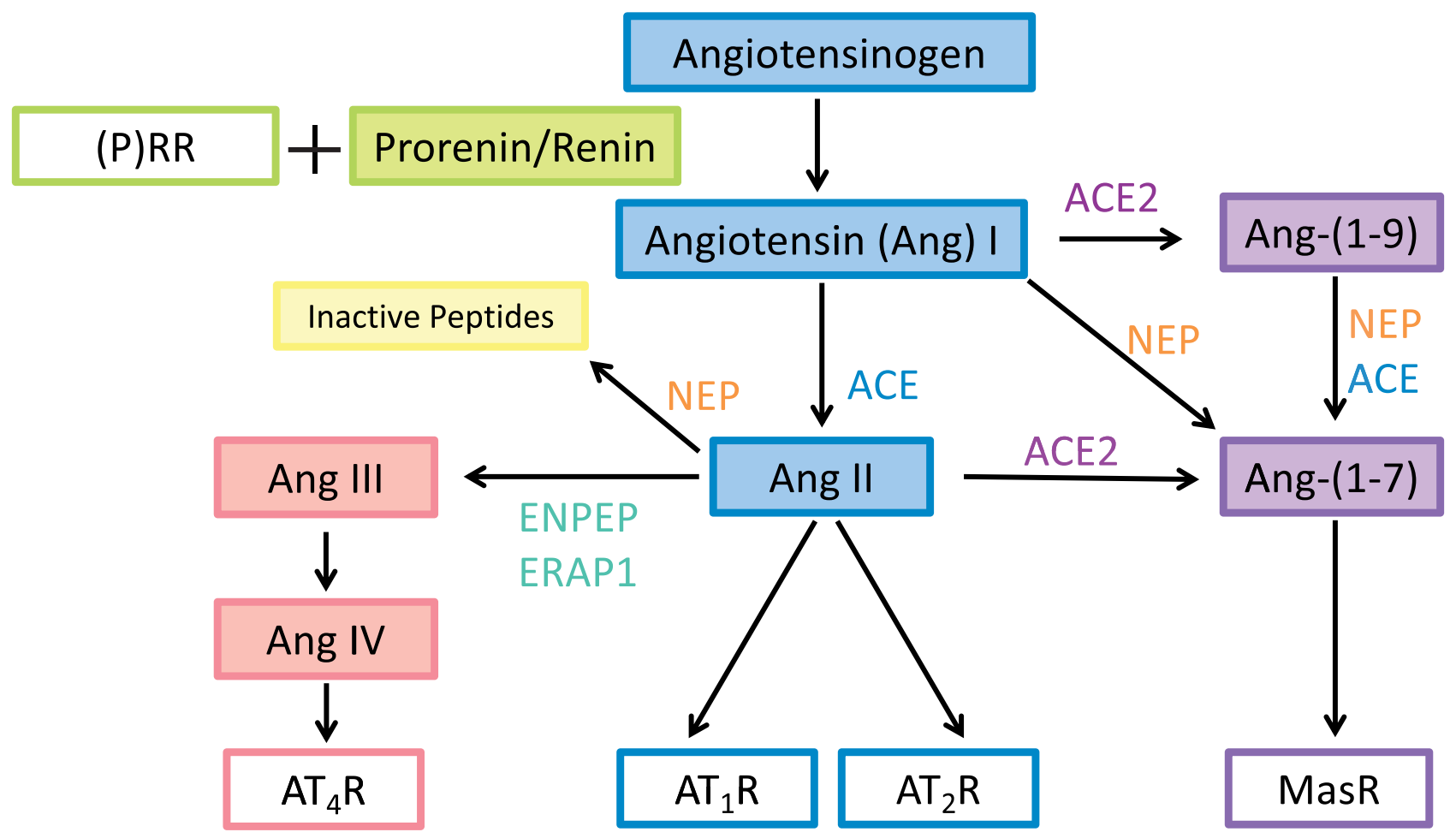

Figure 1 The renin-angiotensin system (RAS) cascade. Prorenin is activated by binding to the (pro)renin receptor ((P)RR) and possibly by proteolysis to cleave angiotensin (Ang) I from angiotensinogen (AGT). ACE then converts Ang I to the biologically active Ang II. Ang II can bind to angiotensin II type 1 receptor (AT1R) to promote proliferation, angiogenesis and vasoconstriction through stimulation of intracellular signalling pathways. Furthermore, angiotensin (Ang) II binds to angiotensin I type 2 receptor $\left(A T_{2} R\right)$ and antagonises $A T_{1} R$ activation. Aminopeptidases including glutamyl aminopeptidase (ENPEP) and endoplasmic reticulum aminopeptidase 1 (ERAP1) allow the conversion of Ang II to Ang III or Ang IV, which act on the $\mathrm{AT}_{4} \mathrm{R}$ and can induce inflammation and hypertrophy. Ang I can also be further converted by angiotensin-converting enzyme 2 (ACE2) to Ang-(1-7). Ang-(1-7) acts upon its receptor Mas. Neprilysin (NEP) can cleave Ang-(1-7) from either Ang I or Ang (1-9). This results in antagonism of Ang II/AT ${ }_{1} \mathrm{R}$ stimulation thus inhibiting proliferation, angiogenesis and vasoconstriction. Alternatively, it can cleave Ang II to two tetrapeptides, inactivating Ang II. 
peptides could affect placental blood flow, restricting nutrient supply and causing FGR.

Although (Ang) II is known to modulate placental blood flow in both uncomplicated and FGR pregnancies (McMillen et al. 2001), in pregnancies associated with idiopathic FGR levels of expression of other proteins that make up the placental RAS have not been determined. Uteroplacental RAS expression is altered in preeclampsia and has been characterised extensively. Components of the vasoconstrictive/pro-inflammatory arm of the RAS ((pro)renin, AGT, ACE, (P)RR and $\mathrm{AT}_{1} \mathrm{R}$ ) are significantly upregulated in placentae and/or decidua from women with preeclampsia when compared with uncomplicated controls (Herse et al. 2007, Anton et al. 2008, Narita et al. 2016). Furthermore, Ang II levels in chorionic villi from women with preeclampsia are significantly higher than placentae from normotensive controls (Anton et al. 2008). Thus, the uteroplacental RAS is activated during preeclampsia, potentially due to inefficient placental perfusion resulting in a hypoxic placenta. Despite the clear link between the placental RAS and placental pathologies, very few studies have investigated expression and function of the RAS in idiopathic FGR placentae.

Therefore, in pregnancies complicated by idiopathic FGR, we have measured levels of expression of the placental RAS and some of its downstream targets and compared these levels with those measured in placentae collected from women with uncomplicated pregnancies.

\section{Materials and methods}

\section{Placental collection}

Placentae were collected from The Royal Women's Hospital Melbourne, with informed consent as approved by the Human Research and Ethics Committee (46/03 and 27/00). Placentae were collected from pregnancies complicated by idiopathic FGR $(n=17)$ as well as from gestational age-matched uncomplicated pregnancies $(n=34)$. The samples tested in this study are a subset of a cohort described previously (Swan et al. 2010). The clinical characteristics of idiopathic FGR placentae and control placentae are described in Table 1. Briefly, the inclusion criteria for idiopathic FGR pregnancies were

1. Birth weight less than the 10th percentile for gestation as determined by the Australian growth charts (Guaran et al. 1994); and

Table 1 Participant characteristics.

\begin{tabular}{lccc}
\hline Characteristics & $\begin{array}{c}\text { Control } \\
(n=34)\end{array}$ & FGR $(n=17)$ & $\boldsymbol{P}$ value \\
\hline Gestation (weeks) & $36.3 \pm 3.6$ & $35 \pm 3.2$ & 0.122 \\
Sex of Newborn & & & $\mathrm{ns}$ \\
$\quad$ Male & $17(50 \%)$ & $8(47 \%)$ & \\
$\quad$ Female & $17(50 \%)$ & $9(53 \%)$ & \\
Birthweight of newborn (g) & $2860 \pm 803.3$ & $1881.4 \pm 667.2$ & 0.0001 \\
Placental weight (g) & $570.4 \pm 147.9$ & $424.2 \pm 91.6$ & 0.0005 \\
\hline
\end{tabular}

Data expressed as mean \pm standard deviation or frequency (\%).
2. At least two of the following diagnoses on antenatal ultrasound:

a. Abnormal Doppler velocimetry (indicated by a change in the end-diastolic blood flow, S/D ratio $>2.5$ for elevated, absent or reversed) (Salafia et al. 1997, Chen et al. 2002),

b. Oligohydramnios indicated by an amniotic fluid index $<7$ (Vik et al. 1997, Volante et al. 2004), or

c. Fetal growth asymmetry as determined by a head circumference-to-abdominal circumference ratio (HC:AC > 1.2) > 95th percentile for gestation (Vik et al. 1997).

Exclusion criteria are described by Swan et al. (2010). Briefly, these included conditions known to be associated with FGR including underlying maternal medical diseases such as, maternal drug and alcohol dependency, maternal smoking, maternal metabolic syndrome (including type 1 and 2 diabetes and gestational diabetes), multiple pregnancies, placental abruption, hypertension, preeclampsia, prolonged rupture of the membranes, foetal congenital anomalies and suspected intrauterine infection. Gestation-matched controls were matched to these FGR cases based on weeks of completed gestation; they had no evidence of obstetric complications that are associated with FGR or placental abnormalities. Placentae were also collected from patients with spontaneous idiopathic preterm labour (excluding women with preterm rupture of membranes) and elective preterm delivery for a condition not affecting the placenta or foetal growth (e.g. maternal breast cancer). Tissue was randomly excised from multiple sites at the periphery of the placenta in both FGR and control cases. Sampling of placental infarcts was avoided. Placental tissue was then washed in phosphate buffered saline (PBS; $0.9 \%$ ) and snap-frozen for subsequent homogenisation for total RNA and protein extraction.

\section{Semi-quantitative real-time reverse transcriptase polymerase chain reaction ( $q P C R)$}

Total RNA was isolated from placentae using the RNeasy Midi Kit (Qiagen) and reverse transcribed using Superscript III (ThermoFisher Scientific) according to the manufacturer's instructions. GPCR was performed in an Applied Biosystems 7500 Real-Time PCR System using SYBR Green for detection. Each reaction contained CDNA reverse transcribed from 10 ng total RNA, SYBR Green PCR master mix (Applied Biosystems) and primers (Table 2). Genes measured include RAS components; prorenin (REN), (P)RR (ATP6AP2), AGT $(A G T), \mathrm{AT}_{1} \mathrm{R}(A G T R 1), \mathrm{ACE}(A C E)$ and ACE2 (ACE2), alternate angiotensin-converting enzymes neprilysin (NEP), ENPEP (ENPEP) and ERAP1 (ERAP1) as well as downstream Ang II/ $\mathrm{AT}_{1} \mathrm{R}$ factors VEGF (VEGF) and PGF (PGF). Dissociation curves to detect non-specific amplifications were generated for all reactions and non-template control samples were included in all assays. mRNA abundance was determined using the $2^{-\Delta \Delta C T}$ method and expressed relative to $\beta$-actin (ACTB) mRNA and a calibrator sample (a term placental sample collected at elective caesarean section). The housekeeping gene was not significantly different between control and FGR placentae and was thus considered stable. 
Table 2 Primers used for qPCR.

\begin{tabular}{|c|c|c|c|c|c|}
\hline \multirow[b]{2}{*}{ Genes } & \multirow{2}{*}{$\begin{array}{l}\text { GenBank } \\
\text { accession \# }\end{array}$} & \multicolumn{2}{|c|}{ Primer sequence $\left(5^{\prime}-3^{\prime}\right)$} & \multirow{2}{*}{$\begin{array}{c}\text { Concentration } \\
(\mathrm{nM})\end{array}$} & \multirow{2}{*}{$\begin{array}{c}\text { Melt } \\
\text { temperature }\left({ }^{\circ} \mathrm{C}\right)\end{array}$} \\
\hline & & Forward & Reverse & & \\
\hline$A C T B$ & NM_001101 & CGCGAGAAGATGACCCAGAT & GAGTCCATCACGATGCCAGT & 1000 & 78 \\
\hline$A C E$ & NM_000789 & AAGCAGGACGGCTTCACAGA & GGGTCCCCTGAGGTTGATGTAT & 200 & 85 \\
\hline ACE2 & NM_021804 & GCAAGCAGCTGAGGCCATTATA & ATCTTCAATCAACTGGCCGC & 400 & 78 \\
\hline$A G T$ & NM_000029 & CAACACСТАCGTCCACТTCCAA & TGTTGTCCACCCAGAACTCСТ & 200 & 62 \\
\hline AGTR1 & NM_000685 & ССТСАGATAATGTAAGСТСАTССАС & GCTGCAGAGGAATGTTCTCTT & 200 & 77 \\
\hline ATP6AP2 & NM_005765 & CСТCATTAGGAAGACAAGGACTATCC & GGGTTCTTCGCTTGTTTTGC & 200 & 60 \\
\hline ENPEP & NM_001977.3 & AGGCAACTTATACAATATCTATC & CATCСАСТGАСТСТTСТT & 200 & 75 \\
\hline ERAP & NM_001040458.2 & TCGGTTGGATGGATAAGA & TAGTCTGAGATTCTGATGGA & 200 & 75 \\
\hline NEP & NM_000902.3 & СTGCTGAGGGGTCACGATT & GAGTGCGATCATTFTCACAGC & 100 & 80 \\
\hline PGF & NM_002632.5 & TTACCGTCACACTCTTCA & CATTCAGCAGGGAAACAG & 100 & 77 \\
\hline VEGFA & M32977 & СТАССТССАССАТGССАAGT & GCAGTAGCTGCGCTGATAGA & 400 & 75 \\
\hline
\end{tabular}

\section{Protein isolation from placental tissue}

Whole cell protein was isolated from FGR and control placenta $(n=17-18)$ using radio-immunoprecipitation assay buffer (RIPA, $50 \mathrm{mM}$ Tris- $\mathrm{HCl}, 158 \mathrm{mM} \mathrm{NaCl}, 1 \%$ Triton X-100, $1 \%$ sodium dodecyl sulphate, SDS) supplemented with a Pierce Halt ${ }^{\mathrm{TM}}$ complete protease inhibitor cocktail kit (Thermo Fisher Scientific) as described previously (Swan et al. 2010). Proteins were quantified using the Pierce BCA Protein Assay Kit according to the manufacturer's instructions (Thermo Fisher Scientific) and used for both ELISAs and immunoblotting.

\section{Measurement of ACE, AGT and Prorenin proteins by ELISA}

Placental ACE, AGT and prorenin proteins were measured using commercially available ELISAs. The human ACE Duoset ELISA kit (R\&D systems) was used to measure placental ACE protein. A human Total Angiotensinogen Assay Kit (ImmunoBiological Laboratories Co., Fujioka-Shi, Japan) was used to measure placental AGT protein. A human prorenin ELISA Kit (Molecular Innovations) was used to measure placental prorenin protein. All proteins were assayed on a single plate. The intra-assay coefficient of variations were 3.6, 6.0 and $9.2 \%$ respectively for $\mathrm{ACE}, \mathrm{AGT}$ and prorenin.

\section{Measurement of ACE2 proteins by immunoblotting}

ACE2 protein was measured by immunoblot. The Novex ${ }^{\circledR}$ NuPAGE® SDS-PAGE Gel System (Thermo Fisher Scientific) was used for electrophoresis of the protein in 4-12\% BisTris $1.5 \mathrm{~mm}$ gels, and then transferred onto PVDF membrane (Thermo Fisher Scientific). Membranes were blocked for $1 \mathrm{~h}$ at room temperature in 5\% BSA (bovine serum albumin) $/ 5 \%$ skim milk powder in $0.1 \%$ TBS-T before being incubated with the primary antibody (1:1000, Polyclonal anti-ACE 2, ab15348 (Abcam)) overnight at $4^{\circ} \mathrm{C}$, in $5 \%$ skim milk powder in $0.1 \%$ TBS-T. The membrane was then incubated with the secondary antibody (1:5000, goat anti-rabbit IgG antibody, 12-348, Millipore) in 3\% Skim milk powder in 0.1\% TBS-T for $1 \mathrm{~h}$ at room temperature. Protein bands were detected using an ECL detection kit (Amersham, GE Healthcare, IL, USA) and imaged using an Amersham Imager 6000 (Amersham, GE Healthcare). Membranes were then stripped in $0.1 \mathrm{M}$ $\mathrm{NaOH}$ to allow detection of the internal control ( $\beta$-actin).
After blocking (5\% skim milk in $0.1 \%$ TBS-T) for $1 \mathrm{~h}$ at room temp, membranes were incubated with the primary antibody (1:3000, Polyclonal anti- $\beta$-actin (Abcam, ab8227)) for a further $1 \mathrm{~h}$ at room temperature. Membranes were then incubated with the secondary antibody and detected as described earlier. The density of each band was corrected for its respective loading control ( $\beta$-actin) and further normalised to an internal control sample (pooled term placenta collected at caesarean section) on each membrane. Samples were run in duplicate and averaged for the final analysis.

\section{Statistical analysis}

Data were analysed using Graphpad Prism, version 7.0. Differences between control and FGR samples were determined using non-parametric Mann-Whitney tests. To determine the associations between abundance of particular RAS mRNAs and putative downstream targets or obstetric outcomes, Spearman's non-parametric correlations were used. Outliers were removed if they lay outside 2-SD from the mean. Significance was set at $P<0.05$ for all data.

\section{Results}

\section{Birth and placental weights of control and FGR pregnancies}

Gestational age and foetal sex were not significantly different between control and FGR cases (Table 1). Birth weights in the FGR cohort were significantly lower than their control counterparts (Table 1). Similarly, placental weights were significantly reduced in FGR pregnancies compared with control (Table 1).

\section{Expression of placental RAS components in FGR placentae}

Prorenin (REN), (pro)renin receptor (ATP6AP2) and $A C E$ mRNA abundance were the same in control and FGR placentae (Fig. 2). Angiotensinogen (AGT) mRNA expression tended to be higher in FGR placentae compared with control; however, this failed to reach significance $(P=0.09$, Fig. 2). Angiotensin II type 1 receptor $(A G T R 1)$ and angiotensin-converting enzyme 

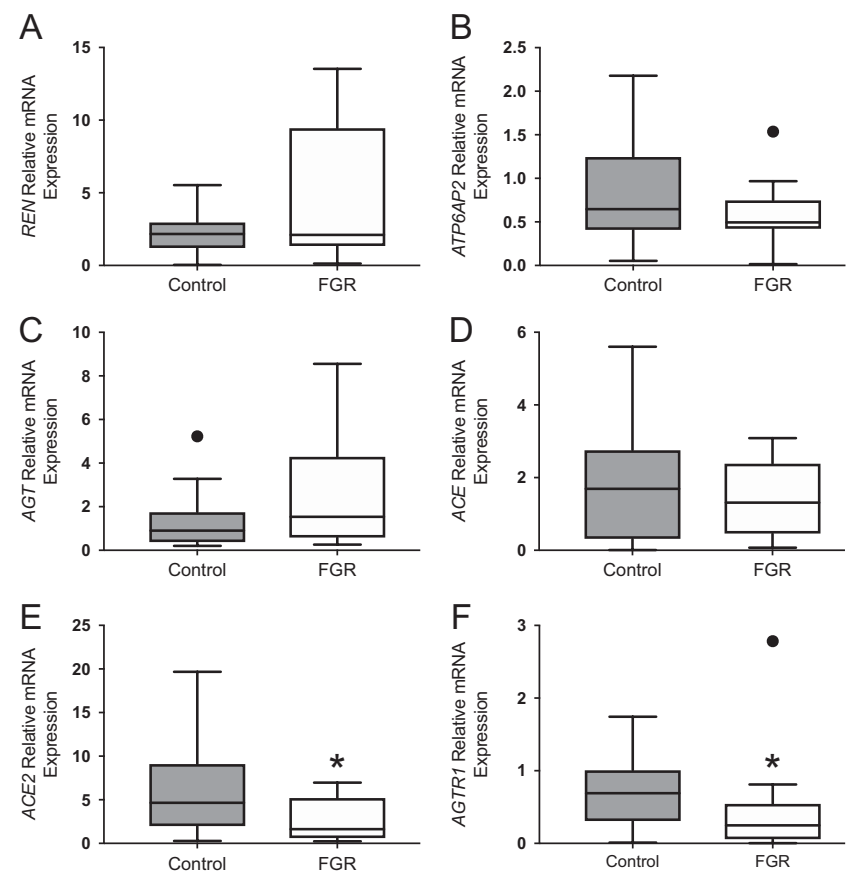

Figure 2 Expression of components of the placental RAS in uncomplicated (control) pregnancies and pregnancies complicated by FGR. (A) REN, (B) ATP6AP2 and (D) ACE mRNAs were the same in control and FGR placentae. (C) AGT mRNA tended to be increased in FGR placentae when compared with control placentae $(P=0.090)$; however, this failed to reach significance. (E) ACE2 and (F) AGTR1 mRNAs were significantly reduced $(P=0.018$ and 0.012 respectively). Single dots represent individual datum that were outside the IQR. Data expressed as median \pm IQ range. $* P<0.05 . n=12-35$.

2 (ACE2) mRNAs were significantly reduced in FGR placentae compared with control placentae (Fig. 2, $P=0.012$ and 0.018$)$.

Prorenin, AGT, ACE and ACE2 proteins were not significantly different between control and FGR placentae (Fig. 3).

\section{Expression of alternative angiotensin processing enzymes and peptidases in control and FGR placentae}

Neprilysin (NEP) mRNA expression was significantly reduced in FGR placentae compared with control placentae (Fig. 4, $P=0.004$ ). Neither glutamyl aminopeptidase (ENPEP) or endoplasmic reticulum aminopeptidase 1 (ERAP1) mRNAs were altered between control and FGR placentae (Fig. 4).

\section{Expression of downstream angiogenic factors}

Expression of $P G F$ mRNA was significantly reduced in FGR placentae when compared with control $(P=0.003$, Fig. 5). VEGF mRNA, however, was unchanged (Fig. 5). AGTR1 and PGF mRNAs were significantly correlated in term placentae from control pregnancies and also tended to be positively correlated in FGR placentae, however, this failed to reach significance (Fig. 6).

\section{Correlations between obstetric outcomes and RAS expression}

In control placentae, both AGT and REN were positively correlated with birth weight (Fig. 7). Furthermore, placental weight was positively associated with AGT mRNA expression in control placentae (Fig. 7). However, in FGR placentae, these correlations were lost (Fig. 7).

Furthermore, ATP6AP2 mRNA expression was negatively associated with both birth weight and placental weight in control placentae (Fig. 8). This association was lost in FGR placentae (Fig. 8).

\section{Discussion}

While the level of expression of the RAS components has been studied in preeclamptic placentae complicated by growth restriction, a comprehensive exploration of this RAS has not been studied in pregnancies complicated by idiopathic FGR. This study is the first to demonstrate that there is dysregulation of components of the placental RAS, suggesting that the placental RAS may contribute to impairment of uteroplacental blood flow in idiopathic FGR.

All the RAS genes studied were found to be expressed in both control and FGR placentae. The level of expression of $A G T$ mRNA tended to be enhanced in FGR placentae and levels of ACE2 and AGTR1 mRNA were reduced. These different levels of expression in FGR placentae of AGT, ACE2 and AGTR1 did not translate into differences in the levels of their proteins for reasons discussed below. The differences in expression of these genes does, however, indicate that associated with idiopathic FGR, there is disturbed expression of the placental RAS that may alter uteroplacental perfusion. If this translates into altered activity of the placental RAS in FGR, then one might suggest that the rate of degradation of Ang II to Ang-(1-7) would be reduced because both ACE2 and NEP expression were reduced. This could result in an increase in placental Ang II levels such as that seen in late gestation preeclamptic placentae (Anton et al. 2008). It is important to note that future studies examining the enzyme activity of ACE2 and NEP as well as the peptide levels of Ang II and Ang-(1-7) in FGR pregnancies are necessary to fully elucidate this.

In FGR placentae, high local levels of Ang II may well cause vasoconstriction and could account for the reduction in expression of AGTR 1 by negative feedback in FGR placentae. Li et al. have shown that there is a significant reduction in AGTR1 mRNA hybridisation signal over the syncytial layer in FGR placentae when compared to control (Li et al. 1998). As well, increased foetal plasma Ang II levels in pregnancies complicated by FGR are associated with a decreased number of 

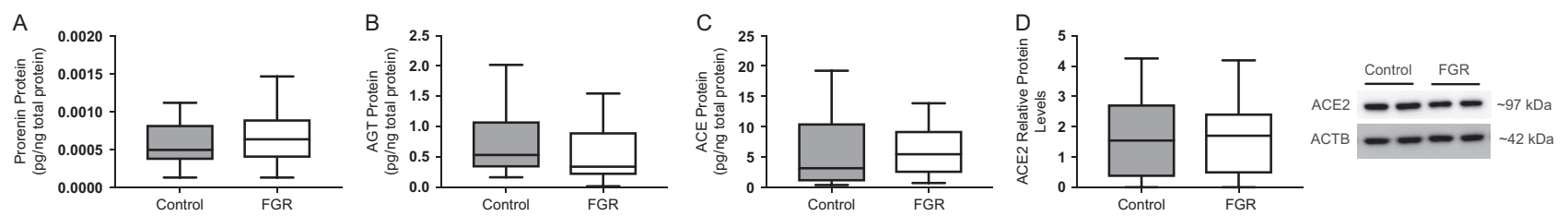

Figure 3 Placental RAS protein levels in uncomplicated (control) and FGR pregnancies. (A) Prorenin, (B) AGT and (C) ACE and (D) ACE2 protein levels were measured by ELISA and were unchanged between control and FGR placentae. Data expressed as median \pm IQR. $n=12-17$.

placental vascular $\mathrm{AT}_{1} \mathrm{R}$-binding sites (McQueen et al. 1990, Kingdom et al. 1993, Knock et al. 1994). The downregulation in AGTR1 in FGR placentae was associated with a significant reduction in PGF (Figs 5 and 6) suggesting that decreased AGTR1 expression might be responsible for reduced growth of the placenta. Ang II is known to stimulate PGF expression via $\mathrm{AT}_{1} \mathrm{R}$ activation in human vascular endothelial cells (Pan et al. 2010). FGR has also been shown by others to be associated with reduced placental PGF (Wu et al. 2017).

A secondary consequence of reduction in the expression of NEP and ACE2 in FGR placentae could be a reduction in the production of Ang-(1-7) resulting in an imbalance in the Ang II/Ang-(1-7) ratio. Ang-(1-7) opposes the vasoconstrictor action of Ang II because it is vasodilator (Schindler et al. 2007). Thus, two factors may be responsible for the reduction in uteroplacental perfusion associated with FGR, increased Ang II and reduced Ang-(1-7), driving vasoconstriction.

As mRNA expression of $\mathrm{AT}_{2} \mathrm{R}$ and Mas receptor tend to be low to undetectable in term placentae (Delforce et al. 2017), they were not examined in the present study. Since the $A T_{1} R$ is the dominant receptor within the placenta and there are reduced ACE2/NEP levels in FGR placenta (and the potential for an increase in
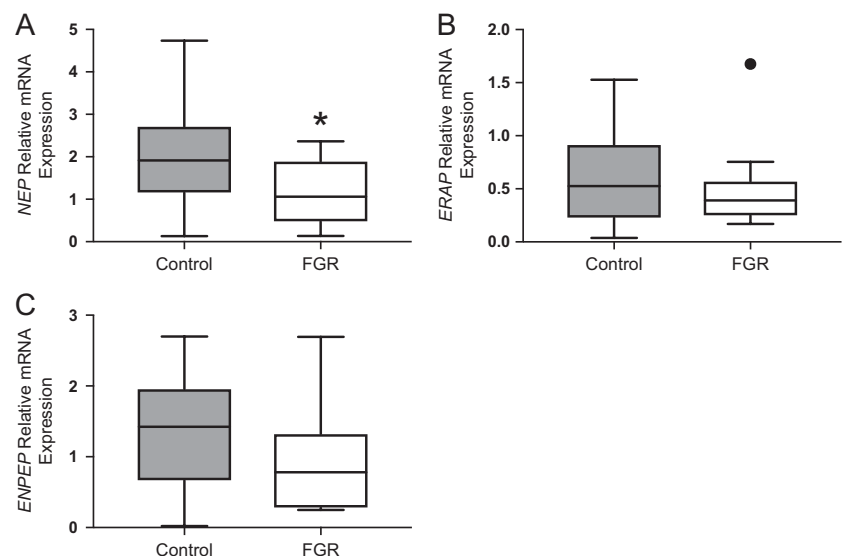

Figure 4 Placental mRNA expression of angiotensin converting enzymes and peptidases in uncomplicated (control) and FGR pregnancies. (A) NEP mRNA expression was significantly reduced in FGR placentae when compared with control $(P=0.004)$. (B) ENPEP and (C) ERAP were not altered between control and FGR placentae. Single dots represent individual datum that were outside the IQR. ${ }^{*} P<0.05$. Data expressed as median \pm IQR. $n=12-32$. the ratio of Ang II/Ang-(1-7)), the overabundance of Ang II stimulating $\mathrm{AT}_{1} \mathrm{Rs}$ may contribute to placental vasoconstriction and negative feedback-induced downregulation of $A T_{1} R$ in FGR placentae.

From as early as 15 -week gestation, women who later deliver a small-for-gestational-age baby have higher circulating Ang-(1-7) levels (Pringle et al. unpublished observations). ACE2 is localised to the syncytial layer of the placenta (Pringle et al. 2011) and the pregnant ACE2knockout (KO) mouse is an animal model of FGR, in that there is placental hypoxia, reduced umbilical blood flow velocity, decreased pup weights and increased pup resorptions (Yamaleyeva et al. 2015). These KO mice also have lower Ang-(1-7) and higher Ang II levels than their pregnant WT counterparts.

It is highly significant that there is in fact a positive correlation in appropriately grown babies between levels of expression of both renin and AGT and birth weight and placental weight, which is lost in pregnancies complicated by idiopathic FGR. This finding suggests that under normal conditions, the placental RAS plays a role in maturation of placental growth and function, as we have previously suggested (Delforce et al. 2017, Wang et al. 2018). The loss of these associations in FGR babies could suggest the placental RAS, including REN and AGT cannot regulate foetal and/or placental growth in FGR placentae thus leading to FGR.

There is evidence that high levels of AGT have an adverse effect on pregnancy outcome. The M235T polymorphism in the AGT gene is associated with both FGR and a higher prevalence of preeclampsia (Zhang et al. 2007). The AGT M235T allele is more frequent in idiopathic FGR pregnancies compared with control
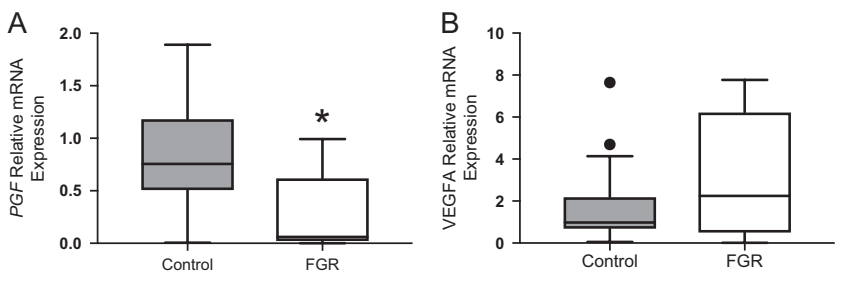

Figure 5 Expression of pro-angiogenic factors in control and FGR placentae. (A) PGF mRNA expression was significantly reduced in FGR placentae when compared with control $(* P=0.003)$. (B) VEGF mRNA expression was unchanged between control and FGR placentae. Single dots represent individual datum that were outside the IQR. ${ }^{*} P<0.05$. Data expressed as median $\pm \mathrm{IQ}$ range. 


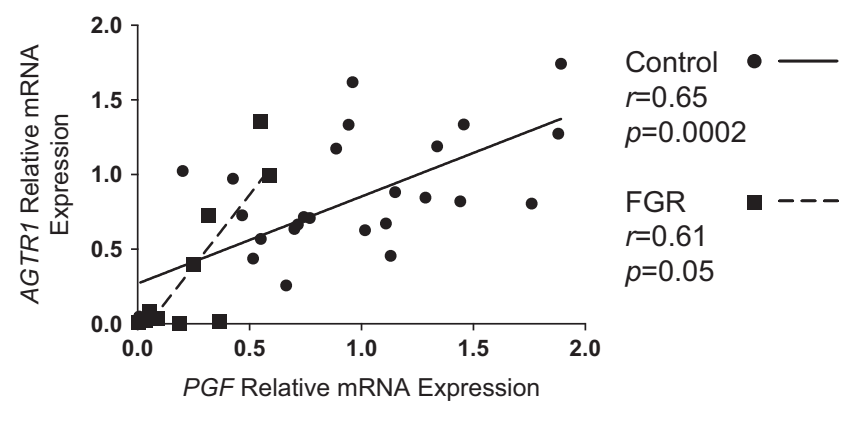

Figure 6 Correlation between AGTR1 and PGF mRNA in control and FGR placentae control placentae $(r=0.65, P=0.0002, n=28)$. FGR placentae $(r=0.61, P=0.05, n=11)$.

( 0.6 vs 0.36 and 0.59 vs 0.38 respectively, both $P<0.001$ ) (Zhang et al. 2003). Further studies identified that this is associated with abnormal spiral artery remodelling (Morgan et al. 1999). We do not know the prevalence of this AGT SNP in the populations we have studied.

Also the T allele has been associated with an increased risk of essential hypertension and increased circulating AGT serum levels (Danser et al. 1998). In first trimester decidua, the presence of the T allele is concomitant with
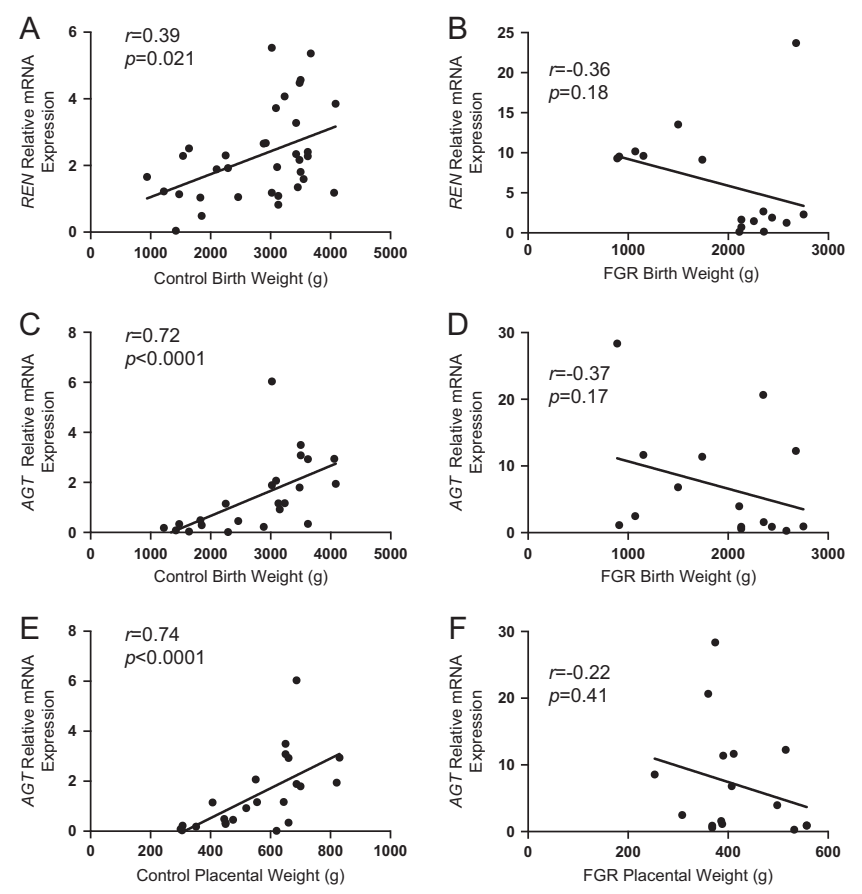

Figure 7 Correlations between REN and AGT mRNAs and control and FGR birth weights and placental weights. (A) REN and (C) AGT mRNAs were positively associated with birth weight in control pregnancies $(r=0.39, P=0.02$ and $r=0.41, P=0.05$ respectively, $n=34$ and 24 respectively). The association between (B) REN and (D) AGT and birth weight was lost in FGR pregnancies ( $n=16$ and 15 respectively). (E) $A G T$ mRNA was also positively associated with placental weight in control pregnancies $(r=0.44, P=0.03, n=24)$, whereas (F) AGT mRNA was not associated with placental weight in FGR pregnancies $(n=16)$. elevated expression of AGT T235 compared to M235 in heterozygous mothers (Morgan et al. 1997).

The case for inappropriate expression of AGT being a causal factor leading to reduced uteroplacental perfusion and idiopathic FGR would have been strengthened if we had shown that AGT protein levels were increased. Possibly the AGT antibody used in our AGT ELISA (developed for use in human plasma) may not bind efficiently to placental AGT because it is often in a polymeric form complexed with other proteins (Lumbers \& Pringle 2014). Importantly, the ELISA used in the current study, picks up both full-length intact AGT (full-length $52 \mathrm{kDa}$ ) as well as des(AI)-AGT, that is AGT which has had the ten amino acids of Ang I cleaved. Therefore, examination of $\operatorname{des}(\mathrm{Al})$-AGT:total AGT levels may also add insight to the function of AGT in FGR placentae.

Furthermore, AGT can be present in both glycosylated and un-glycosylated forms, ranging from molecular weights of 52-75 kDa (Wu et al. 2011). These varying levels and sites of glycosylation can alter the affinity of AGT for renin, however, have no role in intracellular trafficking or secretion of the AGT protein (GimenezRoqueplo et al. 1998). Future experiments could examine AGT via Western blot or alternatively LC-MS/MS to measure different forms of AGT for example, oxidised/ reduced AGT and AGT in complex with other proteins (Zhou et al. 2010, Dahabiyeh et al. 2019). Women with preeclampsia have a significantly lower ratio of reduced AGT:total AGT (Zhou et al. 2010). When renin is bound to $(P) R R$ in tissues, the binding affinity of the oxidised form of AGT is enhanced and results in a four-fold release of angiotensin (Zhou et al. 2010, Lu et al. 2016). A lower
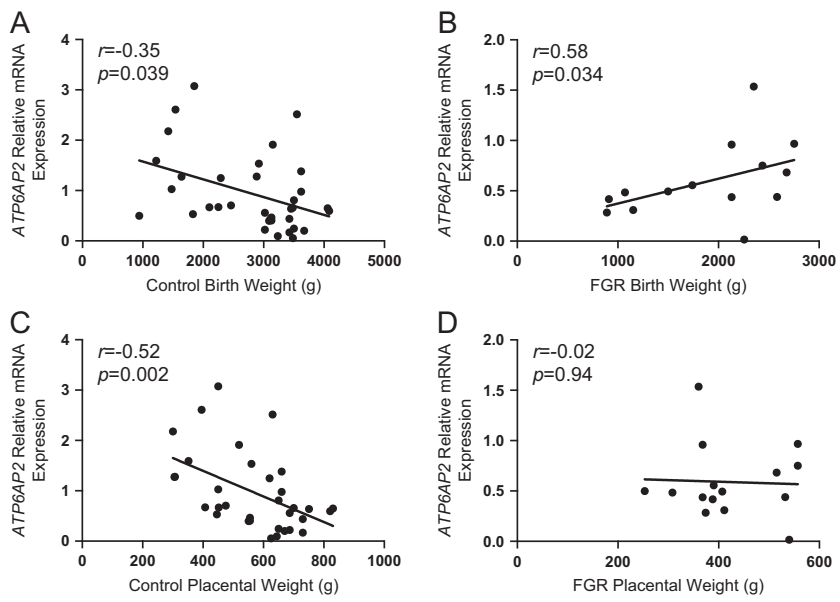

Figure 8 Correlations between ATP6AP2 mRNAs and control and FGR birth weights and placental weights. (A and C) ATP6AP2 mRNA was negatively associated with birth weight and placental weight in control pregnancies $(r=-0.35, P=0.039$ and $r=-0.52, P=0.002$ respectively, $n=35$ and 33 respectively), whereas (B) ATP6AP2 mRNA was positively associated with birth weight in FGR pregnancies ( $r=0.58, P=0.034, n=14)$, and there was no correlation between its expression and placental weight in FGR babies $(D, n=15)$. 
ratio of reduced AGT:total AGT in maternal serum may indicate an enhanced release of angiotensin compared with normotensive controls. A similar mechanism may be occurring in FGR, where the total levels of AGT are not different, but the ratio of oxidised/reduced AGT is altered leading to vasoactive responses.

Alternatively, placental AGT protein could be contaminated with AGT from maternal blood; this could mask any differences in the placental production of AGT. Therefore, we think that the mRNA abundance of AGT rather than its protein levels more closely reflect local placental production of AGT.

Placental ATP6AP2 is increased in women with preeclampsia (Narita et al. 2016), we do not know of any other reports of a negative association between placental ATP6AP2 mRNA and placental or birth weight. One possibility is that the negative association between ATP6AP2 and placental and birth weight is indirect. However, as ATP6AP2 was not significantly altered between FGR and uncomplicated controls, these data should be considered with caution.

It was interesting that the expression of enzymes linking the three major angiotensins (Ang I, II and Ang-(1-7)) were downregulated, while other enzymes associated with the metabolism of angiotensins, namely ENPEP and ERAP1, which are aminopeptidases acting at the $\mathrm{N}$-terminal end of angiotensin resulting in the formation of Angiotensin III and IV, were unaffected. This might suggest that the pattern of dysregulation of the RAS seen in FGR placentae represents a functional response, possibly related to shallow or poor placentation.

In conclusion, placentae from pregnancies with idiopathic FGR are associated with dysregulated expression of the angiotensin-processing enzymes (ACE2 and NEP), which may contribute to an imbalance between the vasoconstrictor and vasodilator arms of the placental RAS such that the vasoconstrictor Ang II pathway predominates. These changes could account for the diagnostic features of idiopathic FGR (i.e. reduced uteroplacental perfusion and decreased foetal growth). There is the potential to target this imbalance and overactivation of the vasoconstrictor arm of the RAS by enhancing the opposing ACE2/Ang-(1-7) pathway through increased production or direct treatment with Ang-(1-7).

\section{Declaration of interest}

The authors declare that there is no conflict of interest that could be perceived as prejudicing the impartiality of the research reported.

\section{Funding}

The authors would like to acknowledge project grant funding from the NHMRC to E R L (GNT1043537). K G P is supported by an ARC Future Fellowship (FT150100179). S E is supported by an NHMRC ECR Fellowship (APP1125539).

\section{References}

Anton L, Merrill DC, Neves LA, Stovall K, Gallagher PE, Diz DI, Moorefield C, Gruver C, Ferrario CM \& Brosnihan KB 2008 Activation of local chorionic villi angiotensin II levels but not angiotensin (1-7) in preeclampsia. Hypertension 51 1066-1072. (https://doi.org/10.1161/ HYPERTENSIONAHA.107.103861)

Barker DJP 2004 Developmental origins of adult health and disease. Journal of Epidemiology and Community Health 58 114-115. (https:// doi.org/10.1136/jech.58.2.114)

Chen CP, Bajoria R \& Aplin JD 2002 Decreased vascularization and cell proliferation in placentas of intrauterine growth-restricted fetuses with abnormal umbilical artery flow velocity waveforms. American Journal of Obstetrics and Gynecology 187 764-769. (https://doi.org/10.1067/ mob.2002.125243)

Dahabiyeh LA, Tooth D, Carrell RW, Read RJ, Yan Y, Pipkin FB \& Barrett DA 2019 Measurement of the total angiotensinogen and its reduced and oxidised forms in human plasma using targeted LC-MS/MS. Analytical and Bioanalytical Chemistry 411 427-437. (https://doi.org/10.1007/ s00216-018-1455-2)

Danser AH, Derkx FH, Hense HW, Jeunemaitre X, Riegger GA \& Schunkert H 1998 Angiotensinogen (M235T) and angiotensin-converting enzyme (l/D) polymorphisms in association with plasma renin and prorenin levels. Journal of Hypertension 16 1879-1883. (https://doi. org/10.1097/00004872-199816121-00005)

Delforce SJ, Lumbers ER \& Pringle KG 2017 Regulation of the prorenin - angiotensin system by oxygen and miRNAs; parallels between placentation and tumour development? Placenta 56 27-33. (https://doi. org/10.1016/j.placenta.2017.03.007)

Gafford JT, Skidgel RA, Erdos EG \& Hersh LB 1983 Human kidney 'enkephalinase', a neutral metalloendopeptidase that cleaves active peptides. Biochemistry 22 3265-3271. (https://doi.org/10.1021/ bi00282a035)

Ghidini A 1996 Idiopathic fetal growth restriction: a pathophysiologic approach. Obstetrical and Gynecological Survey 51 376-382. (https:// doi.org/10.1097/00006254-199606000-00023)

Gimenez-Roqueplo AP, Celerier J, Lucarelli G, Corvol P \& Jeunemaitre X 1998 Role of $\mathrm{N}$-glycosylation in human angiotensinogen. Journal of Biological Chemistry 273 21232-21238. (https://doi.org/10.1074/ jbc.273.33.21232)

Guaran RL, Wein P, Sheedy M, Walstab J \& Beischer NA 1994 Update of growth percentiles for infants born in an Australian population. Australian and New Zealand Journal of Obstetrics and Gynaecology 34 39-50. (https://doi.org/10.1111/j.1479-828X.1994.tb01037.x)

Herse F, Dechend R, Harsem NK, Wallukat G, Janke J, Qadri F, Hering L, Muller DN, Luft FC \& Staff AC 2007 Dysregulation of the circulating and tissue-based renin-angiotensin system in preeclampsia. Hypertension $\mathbf{4 9}$ 604-611. (https://doi.org/10.1161/01.HYP.0000257797.49289.71)

Ito M, Itakura A, Ohno Y, Nomura M, Senga T, Nagasaka T \& Mizutani S 2002 Possible activation of the renin-angiotensin system in the fetoplacental unit in preeclampsia. Journal of Clinical Endocrinology and Metabolism 87 1871-1878. (https://doi.org/10.1210/jcem.87.4.8422)

Kingdom JC, McQueen J, Connell JM \& Whittle MJ 1993 Fetal angiotensin II levels and vascular (type I) angiotensin receptors in pregnancies complicated by intrauterine growth retardation. British Journal of Obstetrics and Gynaecology 100 476-482. (https://doi. org/10.1111/j.1471-0528.1993.tb15276.x)

Knock GA, Sullivan MH, McCarthy A, Elder MG, Polak JM \& Wharton J 1994 Angiotensin II (AT1) vascular binding sites in human placentae from normal-term, preeclamptic and growth retarded pregnancies. Journal of Pharmacology and Experimental Therapeutics 271 1007-1015.

Lackman F, Capewell V, Gagnon R \& Richardson B 2001 Fetal umbilical cord oxygen values and birth to placental weight ratio in relation to size at birth. American Journal of Obstetrics and Gynecology 185 674-682. (https://doi.org/10.1067/mob.2001.116686)

Li X, Shams M, Zhu J, Khalig A, Wilkes M, Whittle M, Barnes N \& Ahmed A 1998 Cellular localization of AT1 receptor mRNA and protein in normal placenta and its reduced expression in intrauterine growth restriction. 
Angiotensin II stimulates the release of vasorelaxants. Journal of Clinical Investigation 101 442-454. (https://doi.org/10.1172/JCI119881)

Lu H, Cassis LA, Kooi CW \& Daugherty A 2016 Structure and functions of angiotensinogen. Hypertension Research 39 492-500. (https://doi. org/10.1038/hr.2016.17)

Lumbers ER \& Pringle KG 2014 Roles of the circulating renin-angiotensinaldosterone system in human pregnancy. American Journal of Physiology: Regulatory, Integrative and Comparative Physiology 306 R91-R101. (https://doi.org/10.1152/ajpregu.00034.2013)

Lyall F, Robson SC \& Bulmer JN 2013 Spiral artery remodeling and trophoblast invasion in preeclampsia and fetal growth restriction: relationship to clinical outcome. Hypertension 62 1046-1054. (https:// doi.org/10.1161/HYPERTENSIONAHA.113.01892)

McMillen IC, Adams MB, Ross JT, Coulter CL, Simonetta G, Owens JA, Robinson JS \& Edwards LJ 2001 Fetal growth restriction: adaptations and consequences. Reproduction 122 195-204. (https://doi.org/10.1530/ rep.0.1220195)

McQueen J, Kingdom JC, Jardine AG, Connell JM \& Whittle MJ 1990 Vascular angiotensin II and atrial natriuretic peptide receptors in normal and growth-retarded human placentae. Journal of Endocrinology 126 341-347. (https://doi.org/10.1677/joe.0.1260341)

Miller SL, Huppi PS \& Mallard C 2016 The consequences of fetal growth restriction on brain structure and neurodevelopmental outcome. Journal of Physiology 594 807-823. (https://doi.org/10.1113/JP271402)

Morgan T, Craven C, Lalouel JM \& Ward K 1999 Angiotensinogen Thr235 variant is associated with abnormal physiologic change of the uterine spiral arteries in first-trimester decidua. American Journal of Obstetrics and Gynecology 180 95-102. (https://doi.org/10.1016/s0002-9378(99)70156-0)

Morgan T, Craven C, Nelson L, Lalouel JM \& Ward K 1997 Angiotensinogen T235 expression is elevated in decidual spiral arteries. Journal of Clinical Investigation 100 1406-1415. (https://doi.org/10.1172/JCl119661)

Moritz KM, Cuffe JSM, Wilson LB, Dickinson H, Wlodek ME, Simmons DG \& Denton KM 2010 Review: sex specific programming: a critical role for the renal renin-angiotensin system. Placenta 31 (Supplement) S40-S46. (https://doi.org/10.1016/j.placenta.2010.01.006)

Napoleone E, Cutrone A, Cugino D, Amore C, Di Santo A, lacoviello L, de Gaetano G, Donati MB \& Lorenzet R 2012 Inhibition of the reninangiotensin system downregulates tissue factor and vascular endothelial growth factor in human breast carcinoma cells. Thrombosis Research 129 736-742. (https://doi.org/10.1016/j.thromres.2011.11.047)

Narita T, Ichihara A, Matsuoka K, Takai Y, Bokuda K, Morimoto S, Itoh H \& Seki H 2016 Placental (pro)renin receptor expression and plasma soluble (pro)renin receptor levels in preeclampsia. Placenta 37 72-78. (https://doi.org/10.1016/j.placenta.2015.11.007)

Pan P, Fu H, Zhang L, Huang H, Luo F, Wu W, Guo Y \& Liu X 2010 Angiotensin II upregulates the expression of placental growth factor in human vascular endothelial cells and smooth muscle cells. BMC Cell Biology 11 36. (https://doi.org/10.1186/1471-2121-11-36)

Pringle KG, Tadros MA, Callister RJ \& Lumbers ER 2011 The expression and localization of the human placental prorenin/renin-angiotensin system throughout pregnancy: roles in trophoblast invasion and angiogenesis? Placenta 32 956-962. (https://doi.org/10.1016/j.placenta.2011.09.020)

Resnik R 2002 Intrauterine growth restriction. Obstetrics and Gynecology 99 490-496.

Salafia CM, Pezzullo JC, Minior VK \& Divon MY 1997 Placental pathology of absent and reversed end-diastolic flow in growth-restricted fetuses. Obstetrics and Gynecology 90 830-836. (https://doi.org/10.1016/ S0029-7844(97)00473-0)

Schindler C, Bramlage P, Kirch W \& Ferrario CM 2007 Role of the vasodilator peptide angiotensin-(1-7) in cardiovascular drug therapy. Vascular Health and Risk Management 3 125-137.

Shibata E, Powers RW, Rajakumar A, von Versen-Höynck F, Gallaher MJ, Lykins DL, Roberts JM \& Hubel CA 2006 Angiotensin II decreases system A amino acid transporter activity in human placental villous fragments through AT1 receptor activation. American Journal of Physiology: Endocrinology and Metabolism 291 E1009-E1016. (https:// doi.org/10.1152/ajpendo.00134.2006)

Swan BC, Murthi P, Rajaraman G, Pathirage NA, Said JM, Ignjatovic V, Monagle PT \& Brennecke SP 2010 Decorin expression is decreased in human idiopathic fetal growth restriction. Reproduction, Fertility, and Development 22 949-955. (https://doi.org/10.1071/RD09240)

Vik T, Markestad T, Ahlsten G, Gebre-Medhin M, Jacobsen G, Hoffman HJ \& Bakketeig LS 1997 Body proportions and early neonatal morbidity in small-for-gestational-age infants of successive births. Acta Obstetricia et Gynecologica Scandinavica: Supplement 165 76-81.

Volante E, Gramellini D, Moretti S, Kaihura C \& Bevilacqua G 2004 Alteration of the amniotic fluid and neonatal outcome. Acta Bio-Medica 75 (Supplement 1) 71-75.

Wang Y, Lumbers ER, Arthurs AL, de Meaultsart CC, Mathe A, AveryKiejda KA, Roberts CT, Pipkin FB, Marques FZ, Morris BJ et al. 2018 Regulation of the human placental (pro)renin receptor-proreninangiotensin system by microRNAs. Molecular Human Reproduction $\mathbf{2 4}$ 453-464. (https://doi.org/10.1093/molehr/gay031)

Warner MJ \& Ozanne SE 2010 Mechanisms involved in the developmental programming of adulthood disease. Biochemical Journal 427 333-347. (https://doi.org/10.1042/BJ20091861)

Williams PJ, Mistry HD, Innes BA, Bulmer JN \& Broughton Pipkin F 2010 Expression of AT1R, AT2R and AT4R and their roles in extravillous trophoblast invasion in the human. Placenta 31 448-455. (https://doi. org/10.1016/j.placenta.2010.02.014)

Wu C, Lu H, Cassis LA \& Daugherty A 2011 Molecular and pathophysiological features of angiotensinogen: a mini review. North American Journal of Medicine and Science 4 183-190. (https://doi. org/10.7156/v4i4p183)

Wu WB, Xu YY, Cheng WW, Yuan B, Zhao JR, Wang YL \& Zhang HJ 2017 Decreased PGF may contribute to trophoblast dysfunction in fetal growth restriction. Reproduction 154 319-329. (https://doi.org/10.1530/ REP-17-0253)

Yamaleyeva LM, Pulgar VM, Lindsey SH, Yamane L, Varagic J, McGee C, daSilva M, Bonfa PL, Gurley SB \& Brosnihan KB 2015 Uterine artery dysfunction in pregnant ACE2 knockout mice is associated with placental hypoxia and reduced umbilical blood flow velocity. American Journal of Physiology: Endocrinology and Metabolism 309 E84-E94. (https://doi. org/10.1152/ajpendo.00596.2014)

Zhang XQ, Craven C, Nelson L, Varner MW \& Ward KJ 2007 Placental abruption is more frequent in women with the angiotensinogen Thr235 mutation. Placenta 28 616-619. (https://doi.org/10.1016/j. placenta.2006.09.011)

Zhang XQ, Varner M, Dizon-Townson D, Song F \& Ward K 2003 A molecular variant of angiotensinogen is associated with idiopathic intrauterine growth restriction. Obstetrics and Gynecology 101 237-242. (https://doi.org/10.1016/S0029-7844(02)02512-7)

Zhou A, Carrell RW, Murphy MP, Wei Z, Yan Y, Stanley PLD, Stein PE, Pipkin FB \& Read RJ 2010 A redox switch in angiotensinogen modulates angiotensin release. Nature 468 108-111. (https://doi.org/10.1038/ nature09505)

Received 12 December 2018

First decision 23 January 2019

Revised manuscript received 11 June 2019

Accepted 17 June 2019 